\title{
Prolonged in vivo Stinging Nettle Treatment Impacts on Functional Capacity of Leukocytes in Immunologically Mature Chickens
}

\author{
Șandru Carmen Dana, Niculae Mihaela, Pall Emoke, Brudaşcă Florinel, Vasiu Aurel, Silvana Popescu, \\ Cerbu Constantin, Giupana Radu, Vasiu Constantin, Valentin Tudor, Spînu Marina*
}

Department of Clinical Sciences - Infectious diseases, University of Agricultural Sciences and Veterinary Medicine, Str. Manastur no.3-5, Cluj-Napoca, ROMANIA.

\begin{abstract}
Objective: The experiment aimed at establishing the effects of an alcoholic Urtica dioica extract on the in vitro blastogenic response in antigen stimulated, immunologically mature chickens. Materials and Methods: Three equal groups ( $n=17)$ of 47 days old, Rock x Cornish chickens were subjected to oral administration of: a) $0.5 \mathrm{ml} / \mathrm{chicken} /$ day of an alcoholic stinging nettle extract (I), b) $0.5 \mathrm{ml} /$ chicken/day alcohol (II, solvent control), and c) $0.5 \mathrm{ml}$ chicken/day water (III-environment control) for seven days. All birds were injected with $0.5 \mathrm{ml} /$ bird of a $5 \%$ SRBC suspension (days 0 and 7). Leukocyte numbers (Burker Turk method) and their blastogenic capacity (blast transformation test) were monitored on days 0,7 and 14 . The specific response was evaluated against a SRBC lysate. Student's t-test was used to evaluate the statistical significance of the differences. Results and Discussion: The leukocyte numbers increased to from 18,083.33 $\pm 4,879.81 / \mathrm{mm}^{3}$ to $42,833.33 \pm 7,547.99 / \mathrm{mm}^{3}$ by day 14 . In vitro responses to C. officinalis and $E$. angustifolia decreased while SRBC response increased in the nettle treated group. Conclusion: The results did not validate the implemented protocol for the alcoholic stinging nettle treatment. Other administration routes, schemes or dosages should be tested to improve the functional capacity of the leukocytes.
\end{abstract}

Key words: Chicken, Immunologically mature, Leukocytes, Blast transformation, Nettle extract.

\section{INTRODUCTION}

Medicinal plants possess various biological activities and have been used for medicinal purposes. ${ }^{1,2}$ Phytochemical and biological investigation have demonstrate their antimicrobial, antifungal, antitumor, antioxidant, antimicrobial and immunomodulatory activity. ${ }^{3,4}$ Immunomodulation using medicinal plants may provide novel immunomodulatory agents to supplement the present conventional therapy for a variety of diseases. ${ }^{1,5}$ Stinging nettle (Urtica dioica, Urticaceae family) is a wild-growing, widespread perennial plant with marked immunomodulatory, antimicrobial, antitumoral, anti-inflammatory, antioxidant, antiviral, activities. ${ }^{6,7}$ The chemical composition of stinging nettle shows the presence of vitamins $\left(\mathrm{A}, \mathrm{B}, \mathrm{B}_{12}\right)$ acetylcholine, histamine, serotonine, minerals, chlorophyll, salicylic acid, lecithin, carotenoids, flavonoids, sterols and formic acid. ${ }^{8}, 9$ Based on the complex biological activity and chemical composition the present experiment aimed at establishing the effects of an alcoholic Urtica dioica extract on the in vitro blastogenic response in antigen stimulated, immunologically mature chickens.

\section{MATERIAL AND METHODS}

The crossbred Rock x Cornish chickens (47 days old) were randomly allocated to three treatmentgroups ( $\mathrm{n}=17)$. All the groups were
Submission Date: 30-08-2017; Revision Date: 17-11-2017; Accepted Date: 23-11-2017

DOI: 10.5530/ijper.52.4s.81 Correspondence: Marina Spînu, University of Agricultural Sciences and Veterinary Medicine, Faculty of Veterinary Medicine, Str. Manastur 3-5, Cluj-Napoca, ROMANIA. Phone: +40264596384 E-mail: marina.spinu@gmail. com

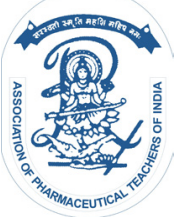

www.ijper.org 
subjected to relatively constant environmental conditions (temperature, relative humidity, ventilation) and similar management practice. A commercially available alcoholic nettle plant extract (Plantextract, Romania) was used. The birds were subjected to oral administration of: a) $0.5 \mathrm{ml} /$ chicken/day of an alcoholic stinging nettle extract(I),b) $0.5 \mathrm{ml} /$ chicken/dayalcohol(II, solventcontrol), and c) $0.5 \mathrm{ml}$ chicken/day water (III-environment control) for seven days. All birds were injected with $0.5 \mathrm{ml} /$ bird of a $5 \%$ SRBC suspension (days 0 and 7 ) and blood sample were collected.

The total number of leukocytes was evaluated using the classical Bürker-Türk method.

In vitro cell-mediated reactivity was assessed by blast transformation test ${ }^{10}$ on days 0,7 and 14 .

The in vitro response was measured against phytohemagglutinin-M (PHA-M, Sigma-Aldrich) and commercial alcoholic extracts for human use of Calendula officinalis and Echinaceea purpureea (Plantextract, Romania) produced according to the German Pharmacopeia. One $\mathrm{ml}$ of each blood sample was diluted with four times the amount of RPMI 1640 (Sigma-Aldrich, USA) supplemented with 5\% FCS and penicillin+streptomycine, at $\mathrm{pH} 7.4$ and placed in 96-sterile-well plate (200 $\mu \mathrm{l}$ per well). The in vitro experimental variants were namely (1) untreated control culture, (2) phytohaemagglutinin-M (PHA) $\left(1 \mu\right.$ per well), (3) $70^{\circ}$ alcohol and (4-5) alcoholic vegetal extracts of Calendula officinalis, and Echinacea purpurea. The specific response was evaluated against a SRBC lysate. Subsequent to an incubation at $37^{\circ} \mathrm{C}$ in a $5 \% \mathrm{CO}_{2}$ atmosphere for $48 \mathrm{~h}$, glucose consumption was evaluated by an ortotoluidine colorimetric method with a spectophotometrical reading at $610 \mathrm{~nm}$ wavelength (SUMAL PE2, Karl Zeiss, Jena, Germany), using the reagent as a blank. ${ }^{11,12}$ The stimulation/inhibition index $(\mathrm{S} / \mathrm{I})$ was calculated as: S/I \%=[(IG-GR)/IG]'100, where S/I = blast transformation index, where IG $=$ the initial glucose concentration in the culture medium and $\mathrm{GR}=$ glucose residue in the sample after incubation. ${ }^{13}$

\section{Statistical analyses}

Student's t-test was used to evaluate the statistical signi ficance of the differences. A value of $p<0.05$ was considered statistically significant. All data were expressed as the mean \pm SD.

\section{RESULTS AND DISCUSSION}

Antibiotics were used as dietary supplements for a long period of time in chickens. The spread of antibiotic resistance at high levels led to a ban on further use of antibiotics as growth promoters, therefore alternative solutions were subject to numerous researches. Plants provide a handy and highly bioavailable source for dietary supplements in farmed animals improving the weight gain and health due to their antibacterial and immune stimulating effects. ${ }^{2,14}$ There is evidence to suggest that herbs, spices and various plant extracts have appetizing and digestion-stimulating properties and antimicrobial effects which stimulate the growth of beneficial bacteria and minimize pathogenic bacterial activity in the gastrointestinal tract of chickens. Immunomodulation using different medicinal plants can offer an alternative to conventional treatment for a variety of infections. ${ }^{1}$

There are many studies on the effect of $U$. dioica. The results of Francišković et al. (2017) ${ }^{8}$ using root and herbal extract of $U$. dioica shows that root extracts can decrease the thromboxane production in human platelets, while the herb extracts of $U$. dioica have inhibitory effect toward 12-LOX (lipoxygenase-type enzyme) pathway, and increase the chemokine release from intestinal epithelial cells.

We have previously reported that subcutaneously injected $U$. dioica alcoholic extract in chicken, showed significant immune stimulating response. ${ }^{14}$ In the present study we examined the possible stimulating potential of $U$. dioica alcoholic extract after oral administration in crossbred Rock x Cornish chickens. As it is shown in Figure 1 the total numbers of leukocytes significantly $(p<0.001)$ increased during the experimental period in all groups. Although non-significant when compared to the other groups, the increase was the highest in the nettle extract treated group. The nettle extract treatment in vivo did not improve the in vitro response of the group

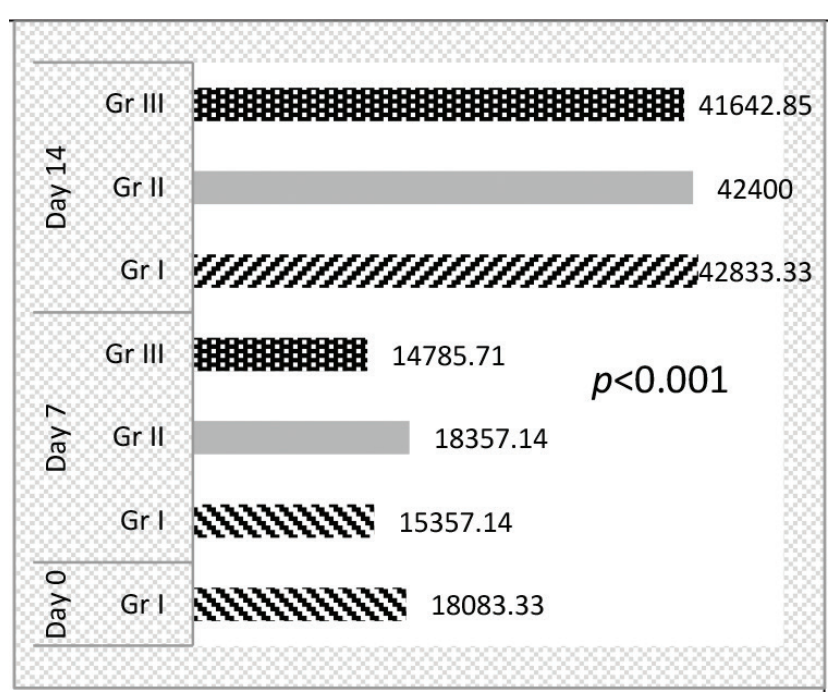

Figure 1: Changes in total leukocyte numbers during the experiment. 


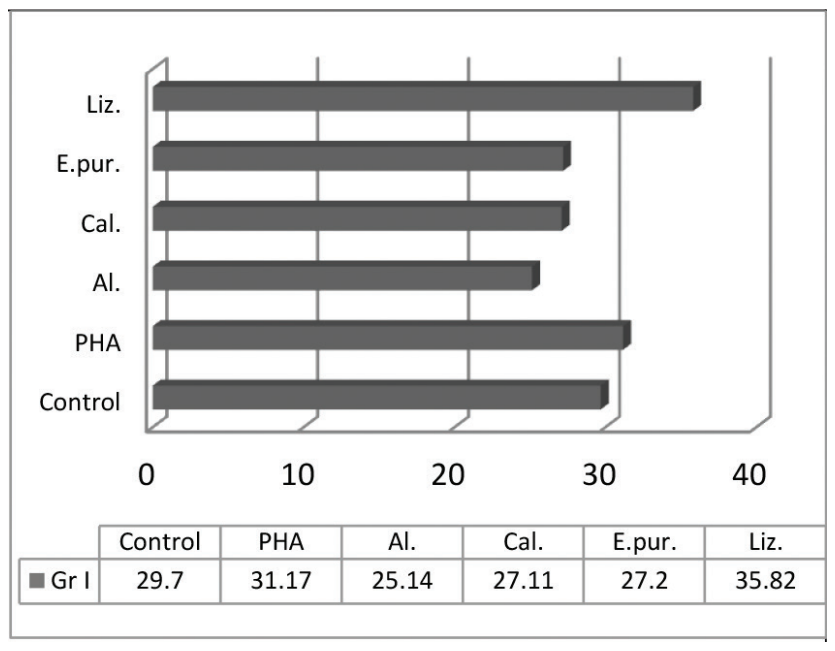

Figure 2: SI\% values prior to the treatment-day 0.

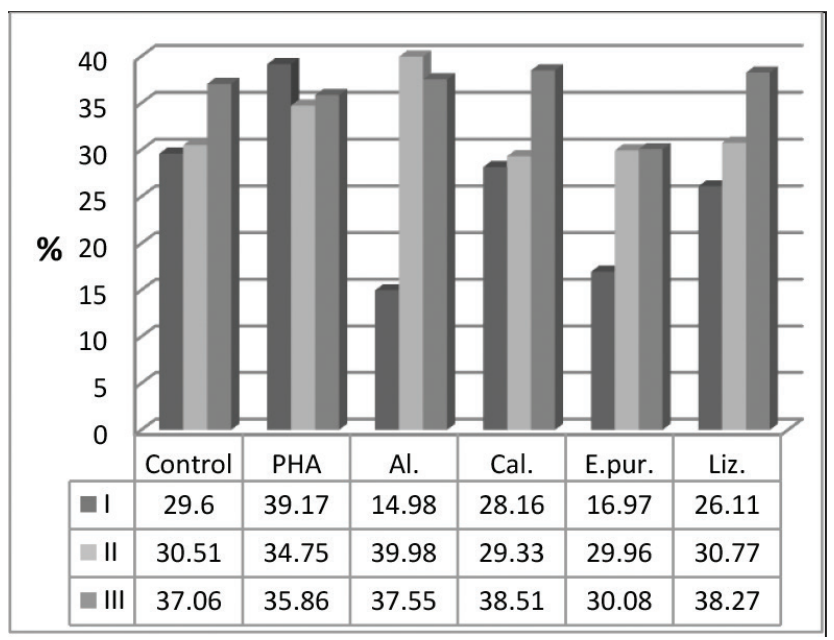

Figure 3: Values of SI\% for the experimental groups after the nettle treatment after 7 days.

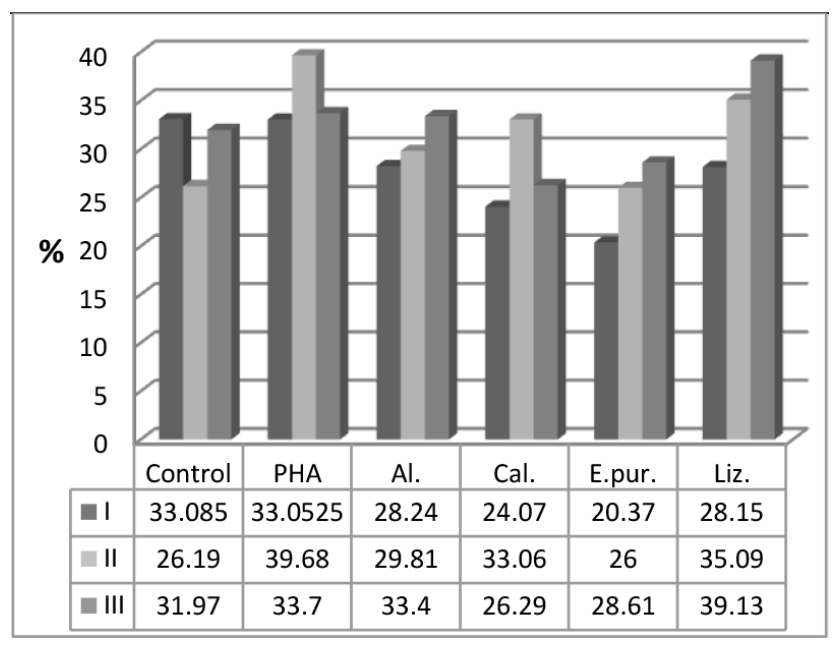

Figure 4: Values of SI\% for the experimental groups at the end of the experiment - day 14 . to the Calendula and Echinacea alcoholic extracts (Figure 2-3). The effect of nettle administration towards the in vitro Calendula response was short-lasting, the decrease being obvious by day 14 (Figure 4). There was an increase in the response of group III control towards the antigen in vitro, but this response was not supported statistically.

\section{CONCLUSION}

The results did not validate the implemented protocol for the alcoholic stinging nettle treatment in significantly stimulating the in vitro to antigen. Other administration routes, schemes or dosages should be tested, to also improve the functional capacity of the leukocytes not only their numbers.

\section{ACKNOWLEDGMENT}

We acknowledge the partial financial support provided by the Ministry of Education (UEFISCDI) grant no PN II 61/2012 Delatbiotox.

\section{CONFLICT OF INTEREST}

The authors certify that they have no affiliations with or involvement in any organization or entity with any financial interest, or non-financial interest in the subject matter or materials discussed in this manuscript.

\section{REFERENCES}

1. Akter K, Barnes EC, Brophy JJ, Harrington D, Yaegl Community Elders, Vemulpad SR, Jamie JF. Phytochemical Profile and Antibacterial and Antioxidant Activities of Medicinal Plants Used by Aboriginal People of New South Wales, Australia. Evidence-Based Complementary and Alternative Medicine. 2016:14.

2. Amirghofran Z, Bahmani M, Azadmehr A, Javidnia K, Miri R. Immunological Investigations, Immunological Investigations Immunomodulatory Activities of Various Medicinal Plant Extracts: Effects on Human Lymphocytes Apoptosis. Immunological Investigations. 2009;38(2):181-92.

3. Francišković M, Gonzalez-Pérez R, Orčić D, Sánchez de Medina F, MartínezAugustin O, Svirčev E, et al. Chemical Composition and Immuno-Modulatory Effects of Urtica dioica L. (Stinging Nettle) Extracts. Phytother. Res. 2017.

4. Getasetegn M, Tefera Y. Biological Activities and Valuable Compounds from Five Medicinal Plants. Nat Prod Chem Res. 2016;4:220.

5. Jantan I, Ahmad W, Syed N, Bukhari A. Plant-derived immunomodulators: an insight on their preclinical evaluation and clinical trials. Front Plant Sci. 2015;6:655

6. Khokhlova IS, Spinu M, Krasnov BR, Degen AA. Immune response to fleas in a wild desert rodent: effect of parasite species, parasite burden, sex of host and host parasitological experience. The $\mathrm{J}$ of Experim. Biol. 2004;207(16):2725-33.

7. Krystofova O, Adam V, Babula P, Zehnalek J, Beklova, Havel L, Kizek R. Effect of various doses of selenite on stinging Nettle (Urtica dioica). International Journal of Environmental Research and Public Health. 2010:7(10):3804-15.

8. Ngugi CC, Oyoo-Okoth E, Mugo-Bundi J, Orina PS, Chemoiwa EJ, Aloo PA. Effects of dietary administration of stinging nettle (Urtica dioica) on the growth performance, biochemical, hematological and immunological parameters in juvenile and adult Victoria Labeo (Labeo victorianus) 
challenged with Aeromonas hydrophila. Fish and Shellfish Immunology. 2015;44(2):533-41.

9. Nobahar Z, Gholipour-Kanani H, Kakoolaki Sh, Jafaryan H. Effect of garlic (Allium sativum) and nettle (Urtica dioica) on growth performance and hematological parameters of beluga (Huso huso). Iranian Journal of Aquatic Animal Health. 2011;(1):63-9. 5.

10. Safamehr A, Mirahmadi M, Nobakht A. Effect of nettle (Urtica dioica) medicinal plant on growth performance, immune responses, and serum biochemical parameters of broiler chickens. International Research Journal of Applied and Basic Sciences. 2012;3(4):721-8.

11. Sandru CD, Niculae M, Popescu S, Pastiu AI, Pall E, Spinu M. Urtica dioica alcoholic extract increases the cell-mediated innate immune potential in chickens. Industrial Crops and Products. 2016;88:15:48-50.
12. Spinu M, Niculae M, Paştiu Al, Şandru CD, Pall E, Vasiu A. Vegetal extracts influence in vitro on the cell-mediated immunity in carnivores depending on health status, target species and plant taxonomy. Industrial Crops and Products. 2016;88:44-7.

13. Spinu M, Brudaşcă GhF, Şandru CD, Niculae M, Rindt K. Influences on the Cell-Mediated Response Following Hippophae rhamnoides Treatment. Analele SNBC. Imunologie. 2008a;8(4):255-60.

14. Spinu M, Brudaşcă GhF, Şandru CD, Niculae M, Ştefan R, Karolyi S. The immunological activity of non-conventional adjuvants. Clujul Medical Veterinar. 2008b;13-14:16-24.

\section{SUMMARY}

- The research aimed at establishing the effects of an alcoholic Urtica dioica extract on the in vitro blastogenic response in antigen (SRBC) stimulated, immunologically mature chickens

- Total leukocyte numbers were counted (BürkerTürk method) and their in vitro blastogenic activity was evaluated by a glucose consumption test.

- The in vitro response to the SRBC antigen and other plant extracts was not augmented by the in vivo stinging nettle treatment.

- Other administration routes, schemes or dosages should be tested, to also improve the functional capacity of the leukocytes not only their numbers.

\section{About Authors}
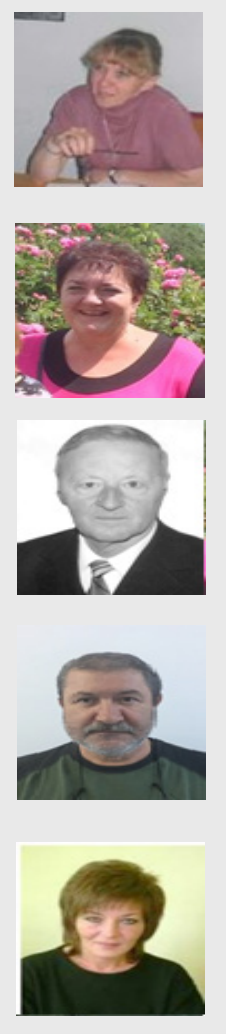

Marina Spinu, DVM, PhD: currently as Professor of Infectious diseases, Head of Department of Clinical Sciences, USAMV, Faculty of Veterinary Medicine, Cluj-Napoca, Romania. Areas of interest: immunology, infectious diseases, antibiotic resistance, alternative therapies (over 500 national and international publications). Under her guidance 17 scholars have been awarded with their PhD degree.

Carmen Dana Sandru, DVM, PhD: currently Associate Professor of Preventive medicine and Veterinary Legislation and ethics, at the USAMV, Faculty of Veterinary Medicine, Cluj-Napoca, Romania. Areas of interest: infectious diseases, preventive medicine, alternative therapies, environment health (over 250 national and international publications).

Constantin Vasiu, DVM, PhD: currently Infectious diseases, Head of Department of Clinical Sciences, USAMV, Faculty of Veterinary Medicine, Cluj-Napoca, Romania. Areas of interest: infectious diseases, preventive medicine, alternative therapies, environment health (over 250 national and international publications).

Florinel Brudasca, DVM, PhD: currently as Professor of Infectious diseases, USAMV, Faculty of Veterinary Medicine, Cluj-Napoca, Romania. Areas of interest: game and exotic animals pathology, infectious diseases, immune stimulation, vaccinology lover 250 national and international publications). Under his guidance 2 scholars have been awarded with their PhD degree, and another one submitted his thesis.

Silvana Popescu, DVM, PhD: currently Associate Professor of Animal Hygiene at the USAMV, Faculty of Veterinary Medicine, Cluj-Napoca, Romania. Areas of interest: environment hygiene, environment health, preventive medicine, animal welfare, alternative therapies, (over 180 national and international publications). 

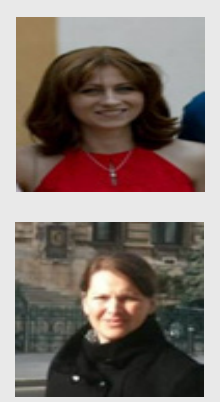

Mihaela Niculae, DVM, PhD: currently Lecturer in Infectious diseases, at the USAMV, Faculty of Veterinary Medicine, Cluj-Napoca, Romania. Areas of interest: infectious diseases, alternative therapies, microbiology, environment health (over 170 national and international publications).

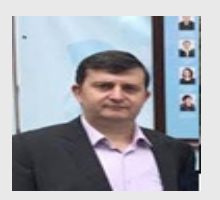

Emoke Pall, DVM, PhD: currently researcher with 11 years of experience, at the USAMV, Faculty of Veterinary Medicine, Cluj-Napoca, Romania. Areas of interest: infectious diseases, cell cultures, stem cells, microbiology/PCR (over 170 national and international publications).

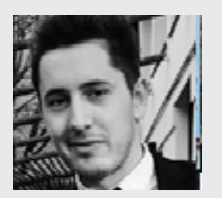

Constantin Cerbu, DVM, PhD: student: currently Assistant with 3 years of teaching experience in Infectious diseases, at the USAMV, Faculty of Veterinary Medicine, Cluj-Napoca, Romania. Areas of interest: infectious diseases, microbiology of the environment, farm animal/fish pathology.

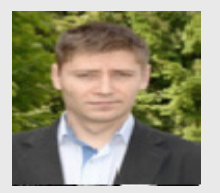

Radu Giupana, DVM: currently PhD student at the USAMV, Faculty of Veterinary Medicine, Cluj-Napoca, Romania. Areas of interest: infectious diseases, microbiology, bovine pathology, alternative therapies.

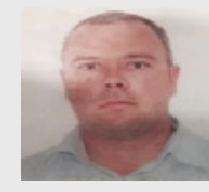

Valentin Tudor, DVM: currently PhD student at the USAMV, Faculty of Veterinary Medicine, ClujNapoca, Romania. Areas of interest: infectious diseases, microbiology, avian pathology, alternative therapies.

Cite this article: Sandru CD, Niculae M, Pall E, Brudasca F, Vasiu A, Popescu S, et al. Prolonged in vivo Stinging Nettle Treatment Impacts on Functional Capacity of Leukocytes in Immunologically Mature Chickens. Indian $\mathrm{J}$ of Pharmaceutical Education and Research. 2018;52(4S):S91-S95 